\title{
Participação familiar no cuidado de crianças com transtorno fonológico
}

\author{
Family participation in the care of children with speech sound \\ disorder
}

\author{
Delta Regina Fernandes ${ }^{1}$ (D), Bernardino Geraldo Alves Souto ${ }^{2}$
}

\begin{abstract}
RESUMO
Objetivo: Investigar o entendimento de pais ou cuidadores de crianças em tratamento fonoaudiológico sobre a importância do envolvimento familiar no projeto terapêutico. Métodos: Por meio de estudo clínico-qualitativo, analisou-se o conteúdo temático de treze entrevistas com pais ou cuidadores de crianças com transtorno fonológico, mediante os referenciais da Humanização do Cuidado em Saúde, do Cuidado Centrado na Pessoa e do Cuidado Centrado na Família. Resultados: Alguns entrevistados consideravam importante o envolvimento familiar e participavam ativamente do cuidado. Outros, entretanto, ressaltaram que fatores contextuais (ambientais e pessoais) dificultavam sua participação no projeto terapêutico fora do cenário ambulatorial. Houve, também, quem não compreendia a necessidade de envolvimento familiar e concentrava sua crítica na assistência. Conclusão: $O$ projeto terapêutico de crianças com transtorno fonológico precisa contemplar os cuidadores e a família no plano de cuidados, tanto quanto a própria criança em tratamento. Nesse projeto, devem ser consideradas as percepções desses cuidadores e familiares relacionadas ao transtorno, contextualizadas em suas contingências existenciais e funcionais.
\end{abstract}

Palavras-chave: Saúde pública; Cuidadores; Assistência centrada no paciente; Transtorno fonológico; Pesquisa qualitativa

\begin{abstract}
Purpose: To investigate the understanding of parents or caregivers of children undergoing speech therapy regarding the importance of family involvement in the therapeutic project. Methods: Through clinical-qualitative study, the thematic content of thirteen interviews with parents or caregivers of children with Speech Sound Disorder (SSD) was analyzed using the references of Humanization of Health Care, Person-Centered Care and Family-Centered Care. Results: Some interviewees considered family involvement to be important and participated actively in care. Others, however, stressed that contextual factors (environmental and personal) hindered their participation in the therapeutic project outside the outpatient setting. Some did not understand the need for family involvement and focused their criticism on assistance. Conclusion: The therapeutic project of children with SSD needs to include caregivers and family in the care plan, as well as the child being treated. In this project, the perceptions of these caregivers and family members related to SSD should be considered and contextualized in their existential and functional contingencies.
\end{abstract}

Keywords: Public health; Caregivers; Patient-centered care; Speech sound disorder; Qualitative research

\footnotetext{
Trabalho realizado no Programa de Pós-graduação em Gestão da Clínica, Universidade Federal de São Carlos - UFSCar - São Carlos (SP), Brasil.

${ }^{1}$ Programa de Pós-graduação em Gestão da Clínica, Centro de Ciências Biológicas e da Saúde, Universidade Federal de São Carlos - UFSCar - São Carlos (SP), Brasil.

${ }^{2}$ Departamento de Medicina, Centro de Ciências Biológicas e da Saúde, Universidade Federal de São Carlos - UFSCar - São Carlos (SP), Brasil.

Conflito de interesses: Não.

Contribuição dos autores: DRF foi responsável pela elaboração do projeto, coleta, análise e interpretação dos dados, revisão bibliográfica, elaboração da dissertação que originou o artigo, redação do manuscrito e padronização das normas, de acordo com os critérios da revista; BGAS foi o orientador do projeto e da dissertação que deu origem ao artigo, participou da análise e interpretação dos dados, da redação e revisão crítica do artigo com importante contribuição intelectual, e da aprovação final da versão para submissão/publicação.
}

Financiamento: Nada a declarar.

Autor correspondente: Delta Regina Fernandes. E-mail: deltaregina@yahoo.com.br

Recebido: Setembro 18, 2020; Aceito: Dezembro 29, 2020 


\section{INTRODUÇÃO}

Visando ofertar cuidado ampliado e integral por meio de equipe multiprofissional, o Sistema Único de Saúde (SUS) do Brasil incorporou a participação do fonoaudiólogo em todos os níveis de atenção ${ }^{(1,2)}$.

Sobre o núcleo da Fonoaudiologia no âmbito desse cuidado integral, destaca-se que a comunicação humana desempenha função imprescindível para uma vida com qualidade e, principalmente, para o desenvolvimento social, emocional, comportamental e cognitivo das crianças. Portanto, os distúrbios da comunicação podem prejudicar o desenvolvimento global infantil, influenciando, consequentemente, a vida da criança e a dinâmica familiar, sendo reconhecidos como importantes questões de saúde pública ${ }^{(3-7)}$.

Dentre os distúrbios que prejudicam a comunicação humana, o transtorno fonológico (TF) apresenta elevada prevalência na população infantil. Caracteriza-se pelo uso inadequado dos sons contrastivos, que pode englobar erros na produção, percepção e na organização mental da produção (armazenamento) dos sons da fala ${ }^{(8-10)}$.

Sendo assim, esse distúrbio configura a dificuldade da criança no aprendizado e na discriminação do sistema fonológico da linguagem ${ }^{(5-7,11,12)}$.

Para a adequação do sistema fonológico desviante, foram propostos diferentes modelos de intervenção, os chamados modelos terapêuticos com base fonológica ${ }^{(13)}$. Entretanto, independentemente da abordagem terapêutica, ressalta-se a importância da participação da família da criança para o cuidado integral e sua eficácia ${ }^{(5-7,14,15)}$.

Embora esse entendimento leve os fonoaudiólogos a tentar incluir os familiares no processo terapêutico, é importante pensar que a participação familiar pode depender de como os pais ou cuidadores percebem o TF e o plano de cuidado proposto, bem como os recursos que dispõem para colaborar ${ }^{(10,12)}$.

Não obstante, são escassas as pesquisas que envolvem as famílias de crianças com diagnóstico de distúrbios da comunicação ${ }^{(6,15,16)}$.

Em uma dessas pesquisas, foi elaborada uma proposta de atendimento fonoaudiológico às crianças com transtorno de linguagem, por meio de uma abordagem que incluiu a família e a escola no processo terapêutico. Os achados demonstraram desenvolvimento significativo no comportamento de cada criança, sobretudo no que se refere à comunicação oral e/ou escrita e à circulação social no âmbito familiar e escolar ${ }^{(15)}$.

Em outro estudo, a autora desenvolveu um programa de acompanhamento a pais de crianças com atraso no desenvolvimento da linguagem e/ou distúrbio específico do desenvolvimento da linguagem. Entre outros aspectos, concluiu que o programa permitiu que os pais se instrumentalizassem sobre quais atividades poderiam realizar no ambiente doméstico, com o intuito de promover a melhora da linguagem de seus filhos, tornando-se parceiros no processo interventivo ${ }^{(16)}$.

A percepção da família e da criança quanto ao impacto do TF foi pesquisada mediante a aplicação de questionários estruturados com questões semiabertas. Por meio de uma abordagem objetiva, os autores concluíram que os pais apresentavam consciência das dificuldades enfrentadas pelos filhos quanto às relações interpessoais, ao estado emocional e à aprendizagem. As crianças percebiam os impactos do distúrbio da comunicação e desenvolveram sentimentos de frustração, timidez e baixa autoestima ${ }^{(6)}$.

Diante disso, pensando em contribuir por meio de uma abordagem mais subjetiva e coletiva a respeito do envolvimento familiar na assistência prestada às crianças com TF, o objetivo principal deste estudo foi investigar o entendimento de um conjunto de pais ou cuidadores sobre a importância do envolvimento da família no processo de cuidado. Os objetivos secundários foram compreender a percepção desses familiares sobre o TF, suas expectativas com o tratamento fonoaudiológico e a forma de organização familiar para o cuidado da criança.

\section{MÉTODOS}

Após aprovação desse estudo pelo Comitê de Ética em Pesquisa em Seres Humanos (CEP) da Universidade Federal de São Carlos (UFSCar), mediante Parecer n ${ }^{\circ}$ 2.024.706, foram entrevistados treze familiares de crianças em tratamento fonoaudiológico no Centro Especializado em Reabilitação (CER) "Dr Eduardo Lauand", serviço inserido na média complexidade da Rede Municipal de Saúde de Araraquara, interior de São Paulo, entre julho e setembro de 2017. Todos os participantes assinaram o Termo de Consentimento Livre e Esclarecido (TCLE).

Os possíveis sujeitos da pesquisa foram indicados por três fonoaudiólogos do setor infantojuvenil do serviço público de saúde referido, por meio do preenchimento de uma planilha que continha dados referentes às crianças com diagnóstico de TF (nome completo, data de nascimento, dia e horário de atendimento, data de início da intervenção). Segundo os diferentes profissionais, todas as crianças e seus acompanhantes recebiam orientações específicas sobre os cuidados domiciliares que interessavam ao tratamento fonoaudiológico, de acordo com a necessidade terapêutica de cada caso.

Os critérios de inclusão adotados foram: ser pai, mãe ou cuidador de criança com diagnóstico de TF, em idade de 4 a 8 anos, independentemente da quantidade de processos fonológicos presentes, da gravidade do transtorno e do tipo de abordagem terapêutica recebida. As crianças estavam em atendimento no mínimo há cinco meses, para a certificação de que fizeram parte da pesquisa somente pais ou cuidadores de crianças na etapa terapêutica que conviviam regularmente com as crianças e que participavam do processo de cuidado.

Foram excluídos os pais ou cuidadores de crianças que apresentavam alguma outra alteração fonoaudiológica potencialmente influente sobre a percepção desses sujeitos no cuidado especificamente fonológico.

Os participantes foram entrevistados individualmente por um dos autores deste estudo, em salas de atendimento do CER "Dr Eduardo Lauand", enquanto as crianças eram atendidas pelos fonoaudiólogos do serviço. As entrevistas duraram entre 30 e 40 minutos e foram gravadas para posterior transcrição.

Assim, o levantamento de dados foi realizado por meio da aplicação dos instrumentos auxiliares em campo (questionário fechado e entrevista semidirigida).

O questionário fechado visava o levantamento de características sociodemográficas das crianças, de acordo com o gênero, idade, escolaridade e pessoas com quem residiam; e de seus pais ou cuidadores (sujeitos da pesquisa), quanto ao grau de parentesco com a criança, gênero, idade, escolaridade, ocupação e renda familiar. 
As entrevistas, por sua vez, se apoiaram em um roteiro semidirigido de questões abertas, no formato de um diálogo que permitiu aos entrevistados falarem livremente sobre os temas de interesse dos objetivos específicos.

Para estimular a fala dos sujeitos sobre os tópicos pretendidos pela pesquisa, iniciou-se a entrevista com a seguinte questão disparadora: "Fale-me sobre seu filho e sobre o tratamento fonoaudiológico que ele faz". Em seguida, foram abordados assuntos relacionados ao modo de organização da família para os cuidados infantis, expectativas sobre a evolução da criança e, por fim, como era a participação do entrevistado no tratamento fonoaudiológico.

As entrevistas foram aplicadas, portanto, segundo o método clínico-qualitativo, que busca pelas reflexões do entrevistado sobre sua experiência com o fenômeno estudado ${ }^{(17)}$, e foram encerradas por saturação ${ }^{(18)}$.

A análise se deu por conteúdo temático, mediante levantamento ideográfico seguido por organização nomotética dos $\operatorname{achados}^{(19)}$. Em termos práticos, apreenderam-se as ideias contidas no discurso de cada entrevistado, organizadas em um corpus coletivo de achados, segundo os temas tratados nas entrevistas. A seguir, esses temas foram distribuídos em categorias definidas pelo diálogo entre os objetivos da pesquisa e os focos apontados pelos entrevistados às perguntas que lhes foram feitas. Por conseguinte, os interesses dos pesquisadores em relação ao que buscavam e as manifestações espontâneas dos entrevistados em relação ao tema abordado receberam igual consideração e tratamento.

A interpretação dos achados, por sua vez, baseou-se nos referenciais teóricos da Humanização do Cuidado em Saúde, do Cuidado Centrado na Pessoa (CCP) e do Cuidado Centrado na Família (CCF).

Sobre esses referenciais, a Humanização do Cuidado em Saúde fundamenta-se no CCP, modelo assistencial que pode ser definido como uma abordagem clínica colaborativa, que se baseia na perspectiva ampliada do cuidado à saúde, admitindo a necessidade do reconhecimento e resposta integral às necessidades de saúde da pessoa. Nessa perspectiva, promove o compartilhamento de poder e responsabilidade entre profissionais e usuários dos serviços, componente que propõe a participação da pessoa na tomada de decisão sobre seus cuidados, reconhecendo, portanto, sua autonomia, a necessidade de fazer as escolhas adequadas ao seu contexto de vida, sua experiência com a própria condição de saúde e seu potencial para efetiva participação em todo o processo de cuidado ${ }^{(20-22)}$.

A inserção da família nesse contexto amplia a abordagem para o âmbito do que se denomina $\mathrm{CCF}$, cujo principal elemento é o relacionamento entre as famílias e os profissionais, que deve ser alicerçado na parceria, colaboração e negociação. A adoção de uma assistência pautada nos princípios desse modelo de atenção à saúde fundamenta-se na compreensão de que o desenvolvimento da criança, bem como o seu bemestar e de toda sua família, são alcançados com maior eficácia quando os profissionais ativam a capacidade dos familiares ou cuidadores para atenderem às necessidades da criança por meio do envolvimento familiar no planejamento das ações terapêuticas e no auxílio do cuidado ${ }^{(10,14,23-25)}$.

\section{RESULTADOS}

\section{A população estudada}

Foram entrevistados 11 mães, um pai e uma tia de crianças em tratamento fonoaudiológico. Esses familiares, com idades entre 22 e 46 anos, possuíam diferentes graus de escolaridade e atividades laborais.

O Quadro 1 apresenta dados referentes aos entrevistados, de acordo com o grau de parentesco com a criança, gênero, idade, escolaridade, ocupação e renda familiar.

Os sujeitos da pesquisa residiam com as crianças com diagnóstico de TF. Das crianças em tratamento, 9 eram do gênero masculino e 4 eram do gênero feminino. Todas recebiam intervenção fonoaudiológica semanalmente e estavam em processo de escolarização adequado para a idade.

O Quadro 2 apresenta os dados que caracterizam as crianças cujos pais ou cuidadores compuseram a amostra.

Quadro 1. Descrição dos sujeitos da pesquisa de acordo com o grau de parentesco com a criança, gênero, idade, escolaridade, ocupação e renda familiar - Araraquara 2017

\begin{tabular}{|c|c|c|c|c|c|c|}
\hline $\begin{array}{l}\text { Nomes } \\
\text { fictícios }\end{array}$ & $\begin{array}{c}\text { Grau de } \\
\text { parentesco } \\
\text { com a criança }\end{array}$ & Gênero & $\begin{array}{c}\text { Idade } \\
\text { (em anos) }\end{array}$ & Escolaridade & Ocupação & Renda familiar \\
\hline 01. Eva & Mãe & $\bar{F}$ & 24 & Ensino médio completo & Dona de casa & $\mathrm{D}$ \\
\hline 02. Cátia & Mãe & $\mathrm{F}$ & 39 & Ensino superior completo & Empresária & $\mathrm{D}$ \\
\hline 03. Vera & Mãe & $\mathrm{F}$ & 46 & Ensino superior completo & Agente educacional & $\mathrm{C}$ \\
\hline 04. Sandra & Mãe & $\mathrm{F}$ & 30 & Ensino médio completo & Dona de casa & B \\
\hline 05. Regina & Mãe & $\mathrm{F}$ & 38 & Ensino médio completo & Agente educacional & B \\
\hline 06. Carla & Mãe & $\mathrm{F}$ & 44 & Ensino superior completo & Dona de casa & C \\
\hline 07. José & Pai & M & 38 & Ensino médio completo & Vigilante & B \\
\hline 08. Célia & Mãe & $\mathrm{F}$ & 40 & Ensino médio completo & Dona de casa & B \\
\hline 09. Sara & Mãe & $\mathrm{F}$ & 30 & Ensino médio completo & Cabelereira & B \\
\hline 10. Irene & Mãe & $\mathrm{F}$ & 38 & Ensino médio completo & Recepcionista & $\mathrm{C}$ \\
\hline 11. Inês & Mãe & $\mathrm{F}$ & 34 & Ensino médio completo & Dona de casa & $E$ \\
\hline 12. Carmen & Mãe & $F$ & 37 & Ensino médio completo & Vigilante & $\mathrm{C}$ \\
\hline 13. Joana & Tia & $\mathrm{F}$ & 22 & Ensino médio incompleto & Manicure & B \\
\hline
\end{tabular}

Legenda: $\mathrm{B}=$ de um a dois salários mínimos; $\mathrm{C}=$ de dois a quatro salários mínimos; $\mathrm{D}=$ acima de quatro salários mínimos; $\mathrm{E}=$ renda não declarada; $\mathrm{M}=$ masculino; $\mathrm{F}=$ feminino 
Quadro 2. Descrição das crianças com transtorno fonológico de acordo com gênero, idade, escolaridade e pessoas com quem residiam Araraquara 2017

\begin{tabular}{|lclll|}
\hline Nomes fictícios & Gênero & \multicolumn{1}{c|}{ Idade } & Escolaridade & \multicolumn{1}{c|}{ Com quem residiam } \\
\hline 01. Pedro & $\mathrm{M}$ & 4 anos e 9 meses & $4^{\mathrm{a}}$ etapa & Pai e mãe \\
02. João & $\mathrm{M}$ & 5 anos e 4 meses & $5^{\mathrm{a}}$ etapa & Pai, mãe e irmã \\
03. Lorenzo & $\mathrm{M}$ & 7 anos e 2 meses & $2^{\circ}$ ano & Pai, mãe e irmão \\
04. Laura & $\mathrm{F}$ & 5 anos e 7 meses & $5^{\mathrm{a}}$ etapa & Pai, mãe e duas irmãs \\
05. Rafael & $\mathrm{M}$ & 6 anos e 10 meses & $1^{\circ}$ ano & Mãe e irmão \\
06. Marcelo & $\mathrm{M}$ & 7 anos e 7 meses & $2^{\circ}$ ano & Pai, mãe e duas irmãs \\
07. Bernardo & $\mathrm{M}$ & 6 anos e 9 meses & $1^{\circ}$ ano & Pai, mãe e irmão \\
08. Matheus & $\mathrm{M}$ & 7 anos e 3 meses & $2^{\circ}$ ano & Pai e mãe \\
09. Alice & $\mathrm{F}$ & 7 anos e 10 meses & $2^{\circ}$ ano & Mãe \\
10. Nicolas & $\mathrm{M}$ & 6 anos e 6 meses & $1^{\circ}$ ano & Pai, mãe e irmão \\
11. Beatriz & $\mathrm{F}$ & 6 anos e 10 meses & $1^{\circ}$ ano & Pai, mãe e irmão \\
12. Henrique & $\mathrm{M}$ & 6 anos e 7 meses & $1^{\circ}$ ano & Pai, mãe e dois irmãos \\
13. Lara & $\mathrm{F}$ & 6 anos e 7 meses & $1^{\circ}$ ano & Mãe, tia, irmão e dois primos \\
\hline
\end{tabular}

Legenda: $M=$ masculino; $F=$ feminino

\section{Categorias temáticas}

Com base na análise dos dados, foram constituídas 4 categorias temáticas: "Percepção dos pais ou cuidadores sobre o TF"; "Expectativas dos pais ou cuidadores sobre a criança com TF"; "Organização da família em função das demandas do projeto terapêutico" e "Percepção dos pais ou cuidadores sobre a importância da sua participação no tratamento fonoaudiológico".

No sentido de descrevê-las na forma como surgiram nas falas dos entrevistados, serão apresentadas e exemplificadas com trechos significativos das entrevistas, nos quais as crianças e seus familiares serão identificados por nomes fictícios.

\section{Percepção dos pais ou cuidadores sobre o TF}

Todos os entrevistados identificaram o TF das crianças. Em alguns relatos, segundo a percepção dos familiares, a alteração do aspecto fonológico da linguagem não influenciou negativamente outros aspectos do desenvolvimento infantil:

[...] ele é uma criança normal, brinca, espontânea, muito inteligente [...]. Mas o pobrema de fala... eu comecei a perceber esse pobrema de fala nele quando ele tava no... no prezinho, [...] que eu vi que ele trocava muito [os sons da fala]. [...] É um excelente aluno [...] muito esperto. $E$ uma criança muito, muito cativa, muito alegre, tem vários amigos. (Regina, sobre seu filho Rafael).

Em contrapartida, outros entrevistados reconheceram o impacto do TF sobre o desenvolvimento das crianças:

Ele fala tudo errado! [...] Houve uma época em que ele se recusava conversar porque ele dizia não conseguir falar corretamente e ele saber que ele chamava a atenção por causa da maneira que ele falava. Então ele começou a se retrair. [...] Ele queria interagir e ele achava que não era capaz de interagir. [...] Eu tinha muito medo dele entrar [...] no $1^{\circ}$ ano e sofrer muito assédio. [...] Às vezes eu tô numa farmácia, tô num supermercado, ele começa conversar comigo, eu vejo que as pessoas olham. [...] Imagina no primeiro ano o quê que esse menino não vai passar, né. (Cátia, sobre seu filho João).
Poderia ter acontecido tanta coisa dificil na vida dele... porque ele poderia ter sido ridicularizado na educação infantil porque não falava direito. Ai ele tava lá, menino na $5^{a}$ etapa falando tititi tatatá. Não entendendo o alfabeto. Então, esse ano ele teria sofrido mais ainda porque ele não iria entender o alfabeto. Ele não ia começar a se alfabetizar. (Vera, sobre seu filho Lorenzo).

\section{Expectativas dos pais ou cuidadores sobre a criança com TF}

As expectativas dos entrevistados sobre a criança com TF referiram-se à reorganização do aspecto fonológico da linguagem e envolviam, entre outros aspectos, suas percepções sobre o tratamento fonoaudiológico.

Houve relatos de satisfação com a intervenção fonoaudiológica e de expectativas de melhora das habilidades de comunicação das crianças. Além disso, alguns participantes esperavam evolução em outras áreas do desenvolvimento infantil, como exemplificado no excerto abaixo:

E eu percebendo assim que isso melhora na alfabetização. Então, é isso que eu espero da fono, que na verdade esse processo que já está acontecendo [...], que ele falasse bem, conseguisse se expressar bem e, assim, não ficasse tímido, não ficasse retraído por causa da fala. [...] Que se soltasse, que não tivesse vergonha de falar, conseguisse se expressar direitinho. (Vera, sobre seu filho Lorenzo).

Alguns participantes afirmaram ter alcançado suas expectativas, mencionando que a eficácia do tratamento fonoaudiológico influenciou positivamente na qualidade de vida das crianças. A esse respeito, uma mãe fez o seguinte comentário:

Fez muito bem. E assim... mudou a vida dele, mudou, né? Então, eu não tenho do que reclamar não. Mudou muito, foi muito bom pra ele, pra ele tanto pra mim. (Regina, sobre seu filho Rafael).

De todo modo, os sujeitos que perceberam como encaminhada a solução de suas angústias derivadas do $\mathrm{TF}$ valorizaram o tratamento e reconheceram sua eficácia, enfatizando a melhora na qualidade de vida e no desenvolvimento da criança, assim como no bem-estar familiar. 
Sob outra perspectiva, um aspecto negativo para alguns entrevistados estava relacionado à duração do tratamento, considerando-se que a necessidade de recuperação era pressionada pelo ambiente de relações:

Olha, na verdade eu achei que fosse ser mais rápido. [...] Eu espero que ela venha a falar bem. O quanto antes melhor porque agora ela já tá começando a passar por bullying na escola. (Sara, sobre sua filha Alice).

Os entrevistados que manifestaram insatisfação com a intervenção fonoaudiológica projetaram os respectivos motivos na lentidão do progresso terapêutico. Nesse sentido, a percepção dos impactos negativos na qualidade de vida da criança possivelmente influenciou a expectativa pela breve reorganização do aspecto fonológico da linguagem.

\section{Organização da família em função das demandas do projeto terapêutico}

O comparecimento e a assiduidade às sessões fonoaudiológicas foram valorizados entre as estratégias de cuidado à criança:

Num deixo ela perder uma consulta [sessão de fonoterapia] porque é muito importante isso pra ela. (Joana, sobre sua sobrinha Lara).

Os familiares mencionaram a realização das tarefas de casa como uma atitude da família voltada para o cuidado da criança com TF, provavelmente em função das orientações dadas pelos fonoaudiólogos durante o processo terapêutico.

Alguns entrevistados empenhavam-se para a realização das tarefas de casa:

Toda segunda-feira vem com uma pastinha de atividades [material fornecido pela fonoaudióloga] pra ela estudar. [...] Durante a semana até chegar a segunda-feira de novo, eu tô estudando com ela. Pra não esquecer, pra não se atrapalhar no dia. [...] A gente senta, estuda. A gente lê, repete. (Inês, sobre sua filha Beatriz).

Contudo, nem sempre os familiares conseguiam garantir a realização das atividades indicadas para o domicílio devido a fatores ambientais e pessoais. Alguns relataram dedicar reduzido tempo para a realização dos trabalhos de casa, pois os aspectos ambientais (trabalho, pouco tempo de convívio com a criança, cuidado com outros filhos e a permanência da criança na escola em período integral) e pessoais (falta de prontidão e cooperação da criança, cansaço e estresse do cuidador) constituíram-se como barreiras para o processo de cuidado da criança com TF.

Uma mulher de 38 anos, agente educacional, mãe de duas crianças, fez o seguinte depoimento sobre a realização das atividades solicitadas pela fonoaudióloga:

Eu ensinava. Ele falava. No pouco tempo que eu tinha porque é uma correria. [...] Tem hora que é dificil porque ele fica o dia inteiro na escola, que ele é periodo integral, né? Eu fazia [suspirou]. Tinha dia que não dava [suspirou]. Vou ser sincera. Tinha dia que não dava. Não dava porque era uma correria, a vida. Tanta coisa pra fazer. Tem hora que ele tava com preguiça e eu já tava estressada também. Pensava assim, hoje não vai dar. (Regina, sobre seu filho Rafael)

\section{Percepção dos pais ou cuidadores sobre a importância da sua participação no tratamento fonoaudiológico}

Alguns entrevistados reconheceram que os familiares eram corresponsáveis pelo cuidado fonológico e que a superação do distúrbio de comunicação seria alcançada somente com o trabalho em conjunto do fonoaudiólogo e da família, ou seja, por meio da parceria e colaboração:

Minha participação eu acho importante, né. Sem eh... essas ajudas que ela [a fonoaudióloga] acaba pedindo pra gente fazer, né, do lado de fora, porque é o lado que a gente mais convive. Vir aqui é importante, mas tem que manter lá também em casa. [...] Uma vez só por semana e menos de uma hora [referindo-se à frequência e ao tempo da sessão terapêutica], né? Então é pouco tempo até mesmo pra criança gravar, absorver. É mais difícil, é bem mais difícil se a gente não tá em casa todo dia. Não tem jeito. [...] E a gente sempre tem um tempinho pra eles, né? (Eva, sobre seu filho Pedro).

Em outros relatos, os entrevistados ressaltaram que os fatores contextuais (ambientais e pessoais) limitavam o envolvimento familiar na intervenção:

Eu acho que eu participo pouco. [risos] [...] Seria mais eh... efetivo o trabalho [tratamento fonoaudiológico], daria mais certo se eu tivesse... eh... condições e tempo. [...] Com duas crianças nessa idade aí que você viu, [...] com tudo pra eu fazer. Não consigo! É que eu não tenho outra pessoa pra fazer comigo. [...] Então, é difícil. Posso me esforçar mais? Posso! Mas, por enquanto, eu não tô conseguindo não. [risos] (Cátia, sobre seu filho João).

Por outro lado, alguns pais ou cuidadores atribuíram à necessidade da participação da família fora do ambiente clínico o número reduzido de sessões e enfatizaram que eram necessárias mais sessões semanais para a melhora da fala da criança. Nesse caso, supõe-se que havia uma percepção reduzida da importância da participação familiar, vista como uma estratégia destinada apenas a suprir a "limitada" oferta do serviço:

O duro é que como é... tipo assim... é pelo governo, é uma vez só por semana. [...] Eu só acho isso. Que deveria ter mais dias porque aí seria mais rápido. Então é como ela [fonoaudióloga] falou pra mim. Vai ser um processo bem... pouquinho... então vai precisa muito da ajuda da gente em casa com ele. (Carmen, sobre seu filho Henrique).

\section{DISCUSSÃO}

As mães foram as principais acompanhantes das crianças para o tratamento fonoaudiológico, conforme observado em outros estudos ${ }^{(26,27)}$.

Além da identificação do TF, no presente estudo, parte dos pais ou cuidadores mencionaram as dificuldades apresentadas pelas crianças e as preocupações familiares relacionadas aos possíveis agravos desinentes do transtorno, como desajustes comportamentais, prejuízo emocional, estigmatização, assédio moral, dificuldades escolares e de interação social.

Da mesma forma, as percepções de alteração do aspecto fonológico da linguagem, de suas possíveis consequências 
negativas e as aflições das pessoas que cuidavam dessas crianças foram descritas pelos entrevistados de outras pesquisas ${ }^{(6,26,28,29)}$.

Nesse sentido, alguns estudos destacaram os problemas escolares e o assédio moral como as alterações de maior ocorrência e as que causavam maiores preocupações ${ }^{(6,26)}$.

As diferentes formas de percepção do TF, com ou sem dificuldades associadas, relacionaram-se com o caráter individualizado da experiência dos cuidadores e das crianças e envolveram sua natureza heterogênea quanto à gravidade e à manifestação. Provavelmente, os informantes que o reconheceram de maneira isolada eram cuidadores de crianças que apresentavam boa inteligibilidade de fala, casos em que os conteúdos de suas mensagens eram compreendidos pela maioria dos interlocutores. De maneira contrária, os pais ou cuidadores que identificaram esse distúrbio da comunicação com dificuldades associadas conviviam com crianças cujas emissões orais eram pouco inteligíveis ou, ainda, ininteligíveis e, por conseguinte, a compreensão das mensagens ficava comprometida. Nesses casos, certamente havia impactos negativos em outras áreas do desenvolvimento infantil.

Sobre a singularidade da experiência com o TF e com as dificuldades associadas, outros autores a descreveram como um fenômeno exclusivo para cada criança e sua família, dependente dos elementos existenciais mobilizados ${ }^{(20,28)}$.

Os participantes esperavam que a intervenção fonoaudiológica promovesse a reorganização do aspecto fonológico da linguagem e, como consequência, melhorasse outras áreas do desenvolvimento infantil. Nos relatos de superação das expectativas, ou seja, nos casos de melhora da habilidade de comunicação, foi percebido que o benefício não se restringiu à criança, mas estendeu-se à família como um todo, especialmente no que diz respeito ao significado do TF no ambiente de relações, repercutindo na autoestima familiar e resultando em um estado de satisfação.

Contudo, diante de sentimentos negativos de alguns familiares, é importante que o fonoaudiólogo reforce a resiliência que a família precisa ter para que reduza a intensidade do sofrimento diante da percepção de lentidão do tratamento em relação à ansiedade de quem cuida da criança, influenciada pela pressão social que sente. Isso implica a necessidade do envolvimento da família na definição das metas da terapia visando assegurar que os objetivos do tratamento abordem suas preocupações e expectativas.

A elaboração de um plano de intervenção em conjunto com os familiares possibilita melhor entendimento do distúrbio da comunicação e provê informações sobre o prognóstico terapêutico, prevenindo possíveis sentimentos e comportamentos negativos relacionados à evolução do sistema fonológico da linguagem e de expectativas maiores que as possibilidades ${ }^{(20,26)}$.

Neste estudo, a organização do cuidado familiar à criança com TF referiu-se ao comparecimento às sessões de tratamento e à realização das atividades indicadas pelos fonoaudiólogos para serem realizadas no dia a dia.

Em outras pesquisas, o compromisso de levar os filhos às sessões fonoaudiológicas e a realização das tarefas de casa também estavam incorporados à percepção do cuidado com as crianças diagnosticadas com distúrbios da comunicação ${ }^{(26,28)}$.

Sobre a percepção da importância da participação familiar, alguns entrevistados compreendiam seu papel no processo terapêutico e a relevância do trabalho em conjunto dos familiares com o profissional. Achado semelhante foi apresentado em outro estudo $^{(30)}$.
O compartilhamento de responsabilidades entre as pessoas envolvidas no processo de cuidado deve acontecer em todos os níveis de atenção à saúde, nos quais os familiares ou cuidadores e os profissionais devem trabalhar em parceria, visando o cuidado integral e sua eficácia ${ }^{(14,15,23,24)}$.

Observou-se que, apesar da percepção da importância da participação da família para além do espaço do ambulatório, alguns cuidadores tinham dificuldades em garantir seu envolvimento no tratamento. Em determinados casos, havia incompatibilidade entre o que os pais consideravam importante e o que, de fato, conseguiam fazer no dia a dia com a criança para a superação da dificuldade fonológica. Diante do exposto e com base em uma abordagem clínica que considere a pessoa em seu contexto de vida, o fonoaudiólogo deve compreender e adequar as necessidades da criança com as possibilidades da família, como parte das práticas do cuidado em saúde. Dessa forma, para facilitar a elaboração de um plano de intervenção que seja flexível, acessível, aculturado e responsivo às necessidades da pessoa assistida e dos seus familiares, deve-se respeitar as diferentes condições, maneiras de cuidar, circunstâncias e histórias que cada família e criança trazem para o contexto terapêutico. Por conseguinte, é preciso identificar o que ajuda os familiares a superarem seus problemas e considerar, empaticamente, a maneira como lidam com as adversidades ${ }^{(12,20,23,24)}$.

Nesse sentido, a pessoa que exerce o papel de cuidador precisa cuidar de si própria e ser cuidada, para que tenha condições de manejar a dificuldade da criança e, assim, desenvolver ações mais resolutivas para o seu desenvolvimento ${ }^{(30)}$. Além disso, diante do acúmulo de compromissos sobre um de seus membros, uma abordagem familiar torna-se imprescindível para a identificação de recursos internos à própria família, que possam ser mobilizados para o enfrentamento do problema. Assim, o profissional da saúde deve identificar e apoiar as potencialidades de cada familiar, aplicando-as ao interesse do projeto terapêutico ${ }^{(20)}$.

Por sua vez, os entrevistados com percepção limitada da importância do envolvimento familiar no cuidado à criança precisam compreender o seu papel no processo interventivo. Essa compreensão pode ser elucidada por meio da sua participação em sessões de orientação e na elaboração das ações terapêuticas.

As sessões de orientação familiar favorecem a incorporação de mudanças de atitudes por parte dos familiares em beneficio das crianças e, portanto, ajudam a determinar os papéis dos envolvidos no cuidado ${ }^{(26,30)}$.

Por fim, o planejamento conjunto do projeto terapêutico possibilita uma parceria colaborativa a partir da compreensão e da pactuação em relação às necessidades da criança, mediadas pela informação e pela autonomia dos sujeitos, em que se articulam seus desejos, possibilidades e necessidades, bem como os da criança ${ }^{(20)}$.

Conforme observado, a contribuição deste estudo foi evidenciar a importância da compreensão que o profissional precisa ter sobre a singularidade do TF, seus significados e repercussões na vida das crianças, dos cuidadores e familiares, no sentido de propor um projeto terapêutico para além da reorganização do aspecto fonológico da linguagem segundo protocolos convencionais. Os fonoaudiólogos precisam compreender o sofrimento causado pelo TF nas crianças e seus familiares, bem como a possibilidade do aumento desse sofrimento devido às expectativas ainda não atendidas durante o tratamento. Essa compreensão pode tornar o trabalho do fonoaudiólogo mais eficiente e eficaz e confortar e aliviar a família diante do 
enfrentamento do TF, de suas repercussões diretas e indiretas e do respectivo tratamento.

Como limitação deste estudo, aponta-se a ausência da consideração entre o grau do $\mathrm{TF}$ e as diferentes percepções dos pais ou cuidadores.

No que tange ao alcance epistemológico desta pesquisa, que teve como fonte cuidadores e familiares de crianças com $\mathrm{TF}$, tornam-se interessantes estudos com foco na percepção de fonoaudiólogos sobre o cuidado dedicado às crianças com TF por tais cuidadores e familiares. Um diálogo entre os achados deste estudo e os dos que se sugerem poderá oportunizar a proposição de estratégias para a qualificação do entendimento entre fonoaudiólogos e famílias de crianças com TF, no âmbito do pacto terapêutico.

A expectativa é que essa qualificação favoreça a estruturação de planos de cuidado de abordagem mais ampliada e mais integral no espaço da longitudinalidade que caracteriza o tratamento de crianças com TF.

\section{CONCLUSÃO}

O projeto terapêutico de crianças com transtorno fonológico precisa contemplar os cuidadores e a família no plano de cuidados, tanto quanto a própria criança em tratamento. Nesse projeto, devem ser consideradas as percepções desses cuidadores e familiares relacionadas ao transtorno, contextualizadas em suas contingências existenciais e funcionais.

A percepção dos familiares sobre o TF e seus possíveis impactos negativos na qualidade de vida das crianças provavelmente influenciou a procura pelo tratamento fonoaudiológico. Alguns sujeitos o identificaram sem qualquer prejuízo associado. Outros entrevistados o reconheceram relacionado aos seus diferentes agravos e, dessa forma, no ambiente de significados das respectivas repercussões na vida da criança e da própria família.

Assim, as expectativas dos familiares ao buscarem pelo tratamento fonoaudiológico se projetaram na reorganização do aspecto fonológico da linguagem e, como consequência, na melhora de outras áreas do desenvolvimento da criança, reconhecidamente prejudicadas pelo TF.

Sobre a percepção da relevância do envolvimento familiar, alguns participantes não compreendiam essa necessidade $\mathrm{e}$ concentravam suas críticas na assistência oferecida. De maneira contrária, alguns consideravam importante o envolvimento dos familiares e participavam ativamente do processo de cuidado. Outros, entretanto, ressaltaram que problemas contextuais dificultavam seu envolvimento no projeto terapêutico fora do cenário ambulatorial.

Desse modo, os familiares empenhavam-se em garantir as visitas ao fonoaudiólogo segundo a agenda pactuada e em seguir as prescrições para o domicílio conforme suas possibilidades, da estrutura familiar e do modo de organização de cada família frente às necessidades terapêuticas. Portanto, esses fatores precisam ser contemplados na estruturação do plano terapêutico proposto pelo fonoaudiólogo.

\section{REFERÊNCIAS}

1. Penteado RZ, Servilha EAM. Fonoaudiologia em saúde pública/ coletiva: compreendendo prevenção e o paradigma da promoção da saúde. Distúrb Comum [Internet]. 2012 Set [citado em 2020 Set 18];16(1):107-16. Disponível em: https://revistas.pucsp.br/index.php/ dic/article/view/11631/8357

2. Santos JN, Maciel FJ, Martins VO, Rodrigues ALV, Gonzaga AF, Silva LF. Inserção dos fonoaudiólogos no SUS/MG e sua distribuição no território do estado de Minas Gerais. Rev CEFAC. 2012 Abr;14(2):196205. http://dx.doi.org/10.1590/S1516-18462011005000088.

3. Zanin LE, Albuquerque IMN, Melo DH. Fonoaudiologia e estratégia de saúde da família: o estado da arte. Rev CEFAC. 2015 Out;17(5):167488. http://dx.doi.org/10.1590/1982-0216201517513414.

4. Longo IA, Tupinelli GG, Hermógenes C, Ferreira LV, Molini-Avejonas DR. Prevalência de alterações fonoaudiológicas na infância na região oeste de São Paulo. CoDAS. 2017;29(6):e20160036. http://dx.doi. org/10.1590/2317-1782/20172016036. PMid:29160334.

5. Furlong L, Serry T, Erickson S, Morris ME. Processes and challenges in clinical decision-making for children with speech-sound disorders. Int J Lang Commun Disord. 2018 Nov/Dez;53(6):1124-38. http:// dx.doi.org/10.1111/1460-6984.12426. PMid:30216607.

6. Simoni SN, Leidow IC, Britz DL, Moraes DAO, Keske-Soares M. Impacto dos distúrbios dos sons da fala: a percepção da família e da criança. Rev CEFAC. 2019 Jul;21(3):e10718. http://dx.doi. org/10.1590/1982-0216/201921310718.

7. Bellon-Harn ML, Morris LR, Manchaiah V, Harn WE. Use of vídeos and digital media in parent-implemented interventions for parents of children with primary speech sound and/or language disorders: a scoping review. J Child Fam Stud. 2020;(Oct):1-13. PMid:33024404.

8. Wertzner HF, Francisco DT, Pagan-Neves LO. Fatores causais e aplicação de provas complementares relacionadas à gravidade no transtorno fonológico. Rev Soc Bras Fonoaudiol. 2012;17(3):299-303. http://dx.doi.org/10.1590/S1516-80342012000300011.

9. Namasivayam AK, Pukonen M, Goshulak D, Yu VY, Kadis DS, Kroll R, et al. Relationship between speech motor control and speech intelligibility in children with speech sound disorders. J Commun Disord. 2013 Maio;46(3):264-80. http://dx.doi.org/10.1016/j. jcomdis.2013.02.003. PMid:23628222.

10. Watts Pappas N, McAllister L, McLeod S. Parental beliefs and experiences regarding involvement in intervention for their child with speech sound disorder. Child Lang Teach Ther. 2016 Jun;32(2):223-39. http://dx.doi.org/10.1177/0265659015615925.

11. Dodd B. Differential diagnosis of pediatric speech sound disorder. Curr Dev Disord Rep. 2014 Set;1(3):189-96. http://dx.doi.org/10.1007/ s40474-014-0017-3.

12. Sugden E, Baker E, Munro N, Williams AL. Involvement of parents in intervention for childhood speech sound disorders: a review of the evidence. Int J Lang Commun Disord. 2016 Nov/Dez;51(6):597-625. http://dx.doi.org/10.1111/1460-6984.12247. PMid:27017993.

13. Gubiani MB, Keske-Soares M. Evolução fonológica de crianças com desvio fonológico submetidas a diferentes abordagens terapêuticas. Rev CEFAC. 2014 Abr;16(2):663-71. http://dx.doi.org/10.1590/ S1516-18462012005000071.

14. Pinto JP, Ribeiro CA, Pettengill MM, Balieiro MMFG. Cuidado centrado na família e sua aplicação na enfermagem pediátrica. Rev Bras Enferm. 2010 Fev;63(1):132-5. http://dx.doi.org/10.1590/S003471672010000100022. PMid:20339768.

15. Gertel MCR. Família e escola: interfaces do atendimento fonoaudiológico de crianças com transtorno de linguagem [tese]. São Paulo: Pontifícia Universidade Católica de São Paulo; 2013.

16. Gonçalves BRL. Programa de acompanhamento a pais na intervenção fonoaudiológica em linguagem infantil [dissertação]. Bauru: Faculdade 
de Odontologia de Bauru, Universidade de São Paulo; 2012. http:// dx.doi.org/10.11606/D.25.2012.tde-01112012-215711.

17. Turato ER. Tratado da metodologia da pesquisa clínico-qualitativa: construção teórico-epistemológica, discussão comparada e aplicação nas áreas da saúde e humanas. 6. ed. Petrópolis: Vozes, 2013.

18. Fontanella BJB, Luchesi BM, Saidel MGB, Ricas J, Turato ER, Melo DG. Amostragem em pesquisas qualitativas: proposta de procedimentos para constatar saturação teórica. Cad Saude Publica. 2011 Fev;27(2):388-94. http://dx.doi.org/10.1590/S0102311X2011000200020. PMid:21359475.

19. Garnica AVM. Algumas notas sobre pesquisa qualitativa e fenomenologia. Interface. 1997 Ago;1(1):109-22. http://dx.doi.org/10.1590/S141432831997000200008 .

20. Lopes JMC. Consulta e abordagem centrada na pessoa. In: Gusso G, Lopes JMC, editores. Tratado de medicina de família e comunidade: princípios, formação e prática. Porto Alegre: Artmed; 2012. p. 113-23.

21. Agreli HF, Peduzzi M, Silva MC. Atenção centrada no paciente na prática interprofissional colaborativa. Interface. 2016 Dez;20(59):90516. http://dx.doi.org/10.1590/1807-57622015.0511.

22. Vaz DV, Jubilini LG, Queiroz LC. Prática centrada no cliente na reabilitação: definição, instrumentos e desafios. Rev Ter Ocup Univ. 2017;28(1):122-7. http://dx.doi.org/10.11606/issn.2238-6149. v28i1p122-127.

23. Johnson BH. Family-centered care: four decades of progress. Fam Syst Health. 2000;18(2):137-56. http://dx.doi.org/10.1037/h0091843.
24. Jolley J, Shields L. The evolution of family-centered care. J Pediatr Nurs. 2009 Abr;24(2):164-70. http://dx.doi.org/10.1016/j.pedn.2008.03.010. PMid:19268238.

25. McKean K, Phillips B, Thompson A. A family-centred model of care in paediatric speech-language pathology. Int J Speech Lang Pathol. 2012 Jun;14(3):235-46. http://dx.doi.org/10.3109/17549507.2011.6 04792. PMid:21936758.

26. Melo RM, Backes FT, Mota HB. Percepções de pais/responsáveis de crianças com desvio fonológico acerca do desvio fonológico e da terapia fonoaudiológica. Rev CEFAC. 2015 Dez;17(6):1802-13. http://dx.doi.org/10.1590/1982-0216201517621314.

27. Souza DMB, Lopes SMB. Percepção da família em relação à atuação fonoaudiológica em um ambulatório. Rev CEFAC. 2015 Fev;17(1):807. http://dx.doi.org/10.1590/1982-0216201515413.

28. McCormack J, McAllister L, McLeod S, Harrison L. Knowing, having, doing: the battles of childhood speech impairment. Child Lang Teach Ther. 2012;28(2):141-57. http://dx.doi.org/10.1177/0265659011417313.

29. Ostroschi DT, Zanolli ML, Chun RYS. Percepção de familiares de crianças e adolescentes com alteração de linguagem utilizando a Classificação Internacional de Funcionalidade, Incapacidade e Saúde (CIF-CJ). CoDAS. 2017;29(3):e20160096. http://dx.doi. org/10.1590/2317-1782/20172016096. PMid:28538828.

30. Santos JLFD, Montilha RCI. Grupo de familiares de indivíduos com alteração de linguagem: o processo de elaboração e aplicação das atividades terapêuticas. Rev CEFAC. 2016 Fev;18(1):184-97. http:// dx.doi.org/10.1590/1982-021620161815115. 